\title{
Education and Reform of Essential Inorganic Chemistry To Freshman in Medical School
}

\author{
Pan Bingli* \\ Public department of chemistry \\ Henan University of Science and Technology \\ Luoyang, China \\ e-mail: pblhaust@126.com
}

Wang Gengxian

Public department of chemistry

Henan University of Science and Technology

Luoyang, China

e-mail:wgx1961@163.com

* Corresponding Author

\begin{abstract}
Essential inorganic chemistry is an important basic course of freshmen in medical school. Students have difficult in learning it and teachers also teach it with difficulty; therefore it is a curriculum with major characteristics. In order to cope with this problem, the author introduces a variety of teaching methods such as case teaching method, chemistry history teaching, multimedia technology and innovative thinking in the chemistry in classroom teaching of freshmen. It has been proved that the above-mentioned ways show the good teaching effect, and they not only arouses the students' learning enthusiasm, but also deepens the understanding and mastery of knowledge of essential inorganic chemistry.
\end{abstract}

Keywords-teaching methods; freshmen; application; inorganic chemistry; innovative ability

\section{INTRODUCTION}

Essential inorganic chemistry is an important basic course in engineering colleges and universities, which is responsible for the basic knowledge of the school of agriculture, forestry, materials, medicine and so on. Essential inorganic chemistry contains basic theories of chemistry and elemental chemistry, especially for the part of basic theories of chemistry with a wide range of knowledge and with full challenge. With national education and reform of college teaching, most of the medical colleges are compressed chemistry course hours. The reduction of chemistry course hours makes the situation worse. This is bound to give considerable difficulty to the teacher's teaching and student's learning. In addition, China has begun to implement the new curriculum teaching system. During the implementation of the new curriculum standards of basic education, different provinces and different regions have the time inconsistency into the experimentation area, and the selection of textbook materials is not uniform. All these factors lead to differences in the basic knowledge of what students grasped, and significantly influence the follow-up

\author{
Gou Minglei \\ Department of chemical engineering \\ Henan University of Science and Technology \\ Luoyang, China \\ e-mail: mingleigou@163.com \\ Guo Jinwu \\ Public department of chemistry \\ Henan University of Science and Technology \\ Luoyang, China \\ e-mail:guojw@haust.edu.cn
}

study in the university. Therefore, the teacher needs to continuously innovate in the teaching method, stimulate students learning interest and enthusiasm in order to achieve good teaching results. In recent years, the author has carried out some exploration in the teaching practice of essential inorganic chemistry, and has achieved good teaching effect.

\section{METHODS OF TEACHING CHEMICAL CONCEPT ABOUT PRACTICAL APPLICATION}

Just as most of the scientific theories obtained with the effort of the former scientists, chemical theory is also unintelligible. In the situation, on the one hand the teacher can introduce the practical application of relevant theories, on the other hand the teacher can tell the history of the theory. Two examples are as follows. In the process of teaching solution chemistry, some theoretical concepts, such as osmotic pressure, can be introduced through the problem of shortage of freshwater resources.

Water resources, especially the problems of shortage of freshwater, are one of the focal problems in the world today. As a whole, the fresh water resources in our country are seriously inadequate. According to experts' prediction, China's water shortage will reach 60000000000 cubic meters in 2030. However, the impurities in the sea usually exist in the form of molecular and ionic forms, and the removal is full of difficulty. Usually by the method of distillation, it needs to consume a lot of energy. Anti osmotic (RO) method is a way which is typically selected through a semi-permeable membrane extracting water from seawater with various salts. In order to achieve the seawater desalination technology, a simple chemical theory of osmotic pressure is used. In the reverse osmosis, energy is consumed on one side of sea water, and pure water passes through a semi-permeable membrane; other ions and molecules retains, thus the separation of the solvent and solute, water and concentration of salt solution is achieved. The theory basis of reverse osmosis desalination is osmotic pressure theory. This is originated 
from the phenomenon that the water molecules in the salt solution flow to water spontaneously, and if an external pressure is loaded, anti-osmosis appears. At present, the reverse osmosis pressure method is important in the industrial water desalination technology (Fig. 1).

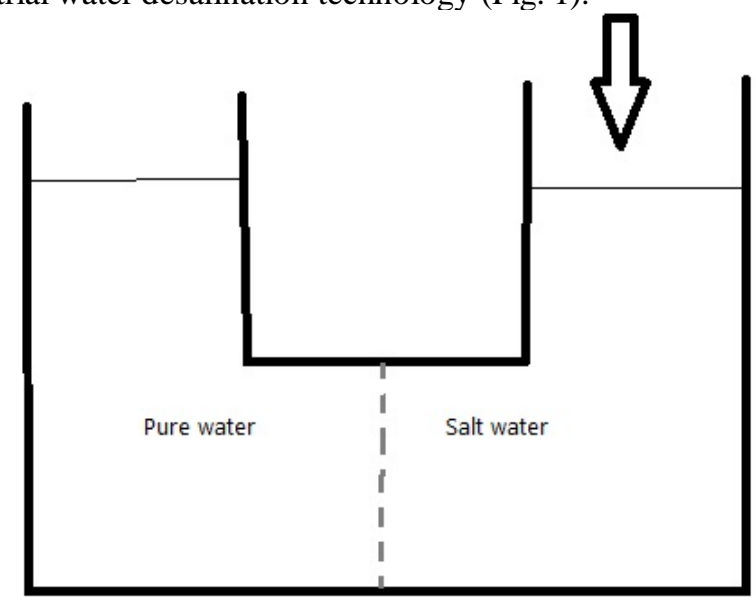

Fig 1. the reverse osmosis pressure method

\section{THE TEACHING OF CHEMISTRY HISTORY AND CASE}

In the teaching process of facing difficulties of essential inorganic chemistry such as atomic structure theory, teachers can often introduce some famous chemical and historical allusions, which can help students to understand context of this kinds of chemical concepts and theories. Through telling some scientific anecdotes, it can enhance learning interest of essential inorganic chemistry for students.

For example, in teaching the dual nature of the electron as the wave and microscopic particles, the teachers can introduce the historical allusions of French scientist De Broglie as a typical example. De Broglie was a very fond of reading, and was awarded a degree in history in 1910. In 1911, he attended the first session of the physics discussion. The Secretary Maurice talked about the issues of quantum nature in the meetings, which aroused his strong interest, and he considered turning to the study of theoretical physics. When he learned that Planck and Einstein's work on quantum field, further passions is aroused about his great interest in physics. After a series of ideological struggle, De Broglie finally gave up the plan to study the history of France and chose the road of studying physics. With more than ten years of hard work, De Broglie eventually won the Nobel Award of 1929.

In 1920 , the case teaching method was founded by Harvard University law school. The target of introduction of the method is to strengthen students' understanding of the legal rules and regulations. Due to good effect of this method, it has been applied to the teaching of sociology, management, economics, medicine and psychology. The teaching process as-designed should be based on the active participation of students. The role of the teacher is not simply giving the lecture but performing the discussion of the specific events with the students in the class; the teacher should gradually summarize the key points of knowledge and solve the practical problem which the students face. The cases of questions, which mainly come from the fact during the practical work or life, are used to carry out teaching in the class. The questions should have the following five characteristics:

knowledgeable;

typical;

pertinence and enlightening;

interesting;

practical.

A typical case is as follows.

Ciprofloxacin lactate is dripping after intravenous amoxicillin-clavulanic acid to one patient in a hospital ward. When the two drugs are mixed in the infusion, a large number of micro yellow needle crystal precipitations appear. But ciprofloxacin that left in the transfusion bottle still keep clear. It was found that the $\mathrm{pH}$ of amoxicillinclavulanic acid was 8.76 . While the $\mathrm{pH}$ was reduced to 6.59, turbidity appears. When the $\mathrm{pH}$ was less than 4.13 , slight yellow needle crystal is precipitated. Therefore, the combination of amoxicillin-clavulanic acid injection with low $\mathrm{pH}$ ciprofloxacin ( $\mathrm{pH} 4$ 5 5. 5) or gentamycin $(\mathrm{pH}$ 4.0 6.0), precipitation will form. Adding $\mathrm{NaOH}$ solution to the system and increasing $\mathrm{pH}$ of solution, the solution becomes clear.

The students are divided in groups of five and begin to discuss. The designed questions are as follows:

What is the definition of acid and base? How does the acid base property of the solution divide? How to determine or calculate the $\mathrm{pH}$ of acid and base solution?

Let the students discuss these problems thoroughly, the teacher gives the following conclusions: Many physiological and pathological phenomena of the human body are related to acid-base balance and sedimentation equilibrium. Acid-base balance of body fluid is one of the three basic balances of human body. Body fluids account for $70 \%$ of body weight, and they all have a certain degree of $\mathrm{pH}$.

The values of $\mathrm{pH}$ maintain stable in a relatively narrow range, and this acid-base balance is an important basis for the maintenance of human life activities. If this balance is destroyed, it will affect the normal activities of life. The acidosis or alkali poisoning will occur, which can lead to various diseases. Clinically, sodium lactate was used to correct the metabolic acidosis, and ammonium chloride was used in the treatment of alkali poisoning. Preparation, analysis, and pharmacological effects of drugs are also often involved in acid base reactions and precipitation reactions. Many drugs themselves are acid or base. In order to ensure the safety and effectiveness of clinical medication, we should pay attention to the differences of $\mathrm{pH}$ among different drugs, and avoid the adverse effects caused by the change of $\mathrm{pH}$. Acid-base property and acidbase balance is the basic theory of acid-base titration which is the first titration method with a very important role in common inorganic chemistry. It is necessary that the relevant theory are fully understood to comprehend the acid-base titration process. Through the case discussion above-mentioned, the students will have a deeper impression of the acid-base balance theory, which is very important.

\section{CULTIVATE STUDENTS' INNOVATIVE ABILITY}

At present, it is one of the important goals of higher education to cultivate students' innovative ability. The cultivation of innovative ability is closely related to the 
comprehensive quality of college students. There are many examples which can be used to cultivate students' innovative ability in essential inorganic chemistry.

The hybrid orbital theory is an important part of molecular structure in the essential inorganic chemistry course, which is the basis for the study of the following elements chemistry. In the traditional teaching of the hybrid orbital theory, the important part focus on the theory of the main points of the teaching, and much time of class education is consumed in the use of the theory to discuss some of the structure of covalent compounds. That is, the processes only pay attention to the content of specific knowledge, but do not pay attention to the scientific process, scientific methods and scientific nature. The targets of cultivating talents lie in building students' scientific literacy, which means not only to master the knowledge itself, but also to understand the process of scientific discovery, to understand the nature of science, to correctly deal with the scientific discovery process. The key results are that the cultivated students are able to flexibly use various scientific methods to solve the real problems. Only at the same time with these qualities, the target of teaching innovation is achieved. Before learning the theory of hybrid orbital, the students have learned the valence bond theory. The formation process and essence of the covalent bond is simply explained by the theory of valence bond, and the characteristics of covalent bond, saturation and so on are successfully explained. But there are some shortcomings in the interpretation of the space structure of molecules, such as the structure of the methane (Fig. 2).

Using the deficiencies of theory of valence bond, the teachers can create the problem situation of some molecule. Through the existed problem, it is natural that scientific method of the hybrid orbital theory is needed to set up. The whole process forms an organic integration of the science education, and by using these teaching arts the students can have a deeper impression of the theory.
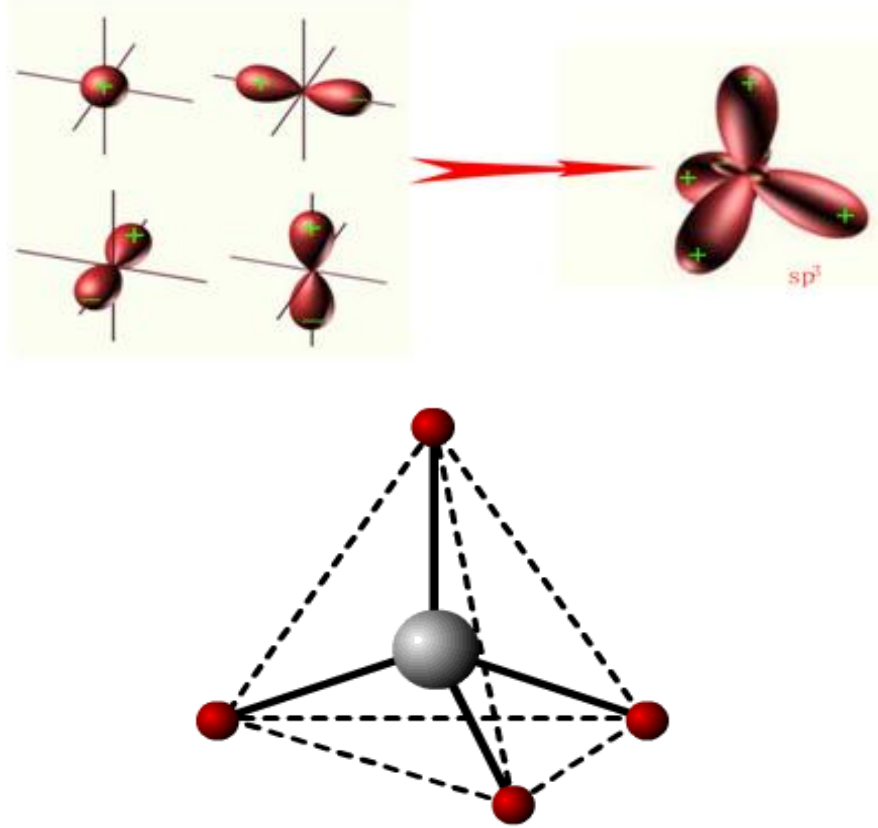

Fig 2. the schematic diagram of the methane
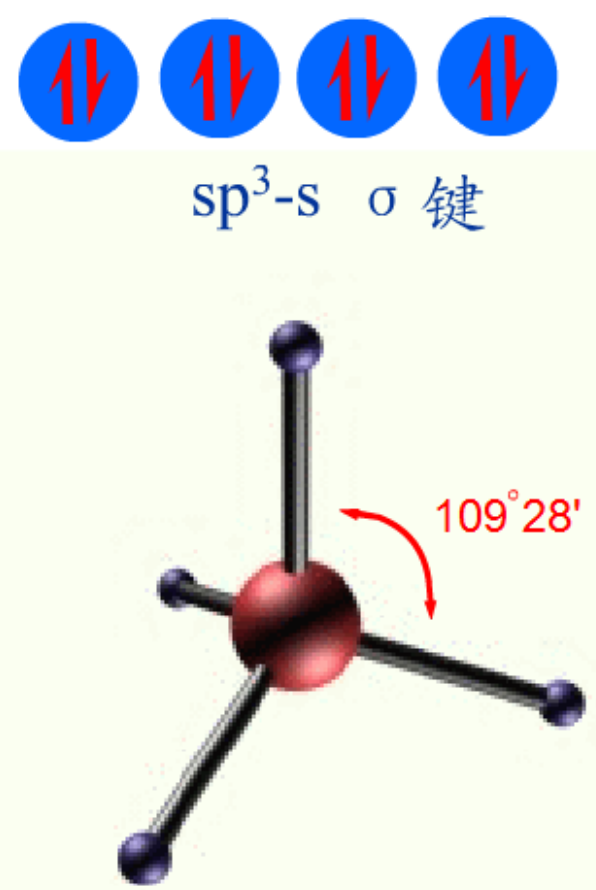

Fig 3. the structure diagram of the methane

\section{THE APPLICATION OF MODERN MULTIMEDIA TECHNOLOGY}

"Labor desire be good work, must first sharpen his tools". With the development of modern educational technology, the technology of multimedia aided teaching in the field of chemistry has been widely used and plays an important role in essential inorganic chemistry. Through the production of vivid animation can make complex concepts and theories become simple and clear, which is not only conducive to students to better understand the chemical concepts and principles, but also to arouse students to learn the enthusiasm and interest of essential inorganic chemistry.

A covalent bond formed in a hydrogen molecule is a typical case. If the process is only described by using narrative techniques directly in a colorless language, it will be hard and difficult to understand. If the teacher use multimedia technology to produce picture and animation during teaching process, the every stage of formation of chemical bonds will be easy to understand. In the animation, the two hydrogen atoms are replaced with little movable balls. When electron spin phases are at the same time, two balls cannot be close to each other. While the electronic spin in opposite directions, two balls can come close to each other and finally fixed in a certain position, thus indicating the formation of chemical bonds. Under the help of multimedia technology, static diagram can be replaced by the animation and planar graphs can be replaced with three-dimensional figure. During the process, text and voice notes are also supplied, which can help students to understand the concepts and theories with difficulty. Due to these vivid illustrations, strong visual effects are displayed and greatly stimulate students' interest 
in learning. At the same time, students' abilities of space imagination are also improved a lot.

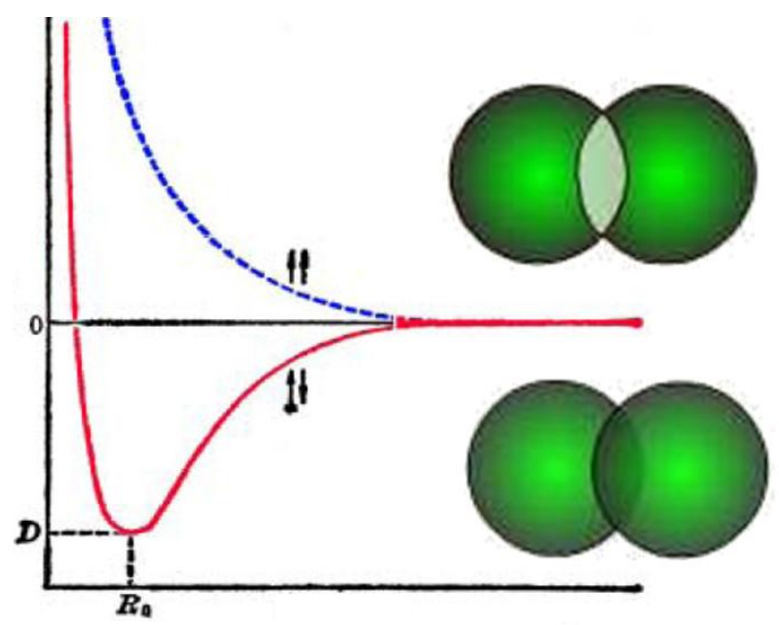

Fig 4. Covalent bond of hydrogen molecule

The modern technologies of multimedia aided teaching have become common arts to display the relative knowledge of the essential inorganic chemistry. The appearance of more and more professional chemical software brings a wide range of teaching technique. After the teacher make full use of the resources, the students will readily obtain the complex theoretical knowledge which is reached before. The authors think that modern technologies of multimedia aided teaching should be used further in the teaching process of essential inorganic chemistry.

\section{CONCLUSIONS}

In order to make the students' subjective initiative put in a prominent position, it is necessary to make full use of the students' subjective initiative and improve the students' interest in the teaching process.
Our teaching and research office used the various new and modern teaching methods to a freshman in essential inorganic chemistry course teaching. Good teaching effects are achieved, and the failure rate of the students is significantly reduced from the initial about $20 \%$ to less than $10 \%$.

\section{ACKNOWLEDGMENT}

The authors will be grateful to Mr. Zheng Xijun for his timely help to make vivid animation. Financial support of this work was provided by the Fund of Henan University of Science and Technology (2008ZDYY004).

\section{REFERENCES}

[1] CATHERINE E. HOUSECROFT AND ALAN G. SHARPE, inorganic chemistry, 2nd ed., Harlow: Pearson, 2005.

[2] Xu Chunxiang, inorganic chemistry, 2nd ed., Beijin: Higher Education Press, 2008.

[3] X. Du, C. Wang. Discussion of Improving Learning Interest of Basic Chemistry. Guangzhou Chemical Industry, vol. 39, Dec. 2011, pp. 162-163.

[4] Q. Ye, Y. Chen, The application of computer multimedia in College Chemistry Teaching, vol. 14, Jun. 1999, pp. 39-41.

[5] Bing Liu, Pijian Zhang. Teaching strategy of hybrid orbital theory based on the cultivation of innovative ability. University Chemistry, vol. 24 , Dec. 2009 , pp. 29-32.

[6] B. Pan, Educational Reform Of College Chemistry To Freshman. Guangzhou Chemical Industry, vol. 42, Aug. 2014, pp. 210-211.

[7] Lu Jiazheng, Jiang Jing Ceng Xiandong Liu Yunjun Guan Xiaoyan Yao Xiuqiong Chen Fei. Case teaching of inorganic chemistry in Medicine College, University Chemistry, vol. 26, Dec. 2011, pp. $16-18$.

[8] J. Yang, Discussion on the technology and application of seawater desalination. Tianjin science and technology, Apr. 2007, pp. 79-81.

[9] Tong Keqin, Zhang Changshui, University Basic Chemistry, 1st ed., Beijin: Chemical Industry Press, 2009.

[10] Xu Chunxiang, Basic Chemistry, 2nd ed., Beijin: People's Health Publishing House, 2007. 